\title{
The prehistoric individual, connoisseurship and archaeological science: the Muisca goldwork of Colombia
}

\author{
Marcos Martinón-Torres ${ }^{1}$ and María Alicia Uribe-Villegas ${ }^{2}$ \\ ${ }^{1}$ UCL Institute of Archaeology, 31-34 Gordon Square, London WC1H OPY, UK \\ ${ }^{2}$ Museo del Oro, Banco de la República, Calle 16 \# 5-41, Bogotá DC, Colombia \\ m.martinon-torres@ucl.ac.uk; muribevi@banrep.gov.co
}

\begin{abstract}
Unlike art historians, archaeologists rarely make systematic attempts at attributing artefacts to individual artisans - they stop at the broader category of 'provenance regions' or 'technical styles'. The identification of archaeological individuals, however, allows detailed insight into the organisation of workshops, knowledge transmission, skill, and the tension between individual and social agency. This paper reviews the potential of archaeological science methods to identify individual artisans through the study of material culture. Focusing on the Muisca votive goldwork of Colombia, it combines stylistic, chemical and microscopic analyses to identify idiosyncratic motor habits, material selections and artistic preferences that allow the identification of individual makers and manufacturing events. The results are informative of the internal dynamics between the Muisca technological tradition, religious behaviour and craft specialists. We conclude by outlining the potentials and challenges of science-based archaeological connoisseurship in other contexts.
\end{abstract}

Keywords: Technical style, cultural transmission, craft organisation, archaeological individual, gold, lost-wax, Colombia, South America, connoisseurship, LA-ICP-MS, pXRF, HLLA glass

\section{Introduction: identifying individual artisans in prehistoric arts and crafts}

Studies of archaeological material culture often search for patterns in the shape, style or decoration of artefacts, or in other traits that require instrumental characterisation such as their microstructure or their chemical or isotopic composition. The groups of objects thus classified are subsequently given behavioural explanations. For example, metal artefacts with the same isotopic signature are thought to derive from the same source, and those with the same style are assigned to a particular cultural affiliation; ceramicsrevealing similar composition, temper and firing regimes are assigned to a particular workshop. With suitable contextual and chronological information, these heuristic groups of objects can be used as the basis to reconstruct broader phenomena such as fluctuations in the provision of raw materials, exchange of goods, or the changes in technology, morphology or other style preferences that result from evolution in sociocultural or economic structures.

In art history studies, 'schools' or traditions are also defined on the basis of traits shared by several creations, typically seen as resulting from a combination of learning traditions and, in some cases, 
patron or customer preferences. However, it is far more common for art historical studies to single out individual artists within broader traditions. Individuals are sometimes identified by their signatures, but attributions are more reliably based on a combination of specific techniques, materials, or gestures that are taken as characteristic of a particular artisan. As such, for example, an unsigned painting can be assigned to a particular artist, a signed one revealed to be a fake, or a single painting can sometimes be shown to be the result of a master and several less skilled assistants that were tasked with the creation of less important parts of the work.

Such 'attribution studies' have a long history in art history, and a key component of them has been 'connoisseurship' - the largely subjective 'eye' or intuition of a few well-reputed art critics who could identify unsigned works and assign them to famous artists. In the $19^{\text {th }}$ century, Giovanni Morelli (1892-3) developed his "scientific method" (Wollheim 1973), which strived to define more consistent criteria for attribution studies (see also Berenson 1902). Among other features, Morelli focused on the execution and style of incidental details of human representations often repeated by artists, such as ears and hands, as characteristic of individual artists. As these body parts were accessory details of the artwork, artists "involuntarily" used "habitual modes of expression" that left diagnostic, recognisable peculiarities (Morelli 1832: 75, quoted in Wollheim 1973: 194). In spite of the fame of the 'Morellian method', art history attributions have remained strongly subjective and reliant on the 'good eye' and skilful rhetoric of a few connoisseurs (e.g. Opperman 1990; Carrier 2003). Only in recent decades has 'technical art history' gained some momentum as a new, less biased form of connoisseurship: with the use of instrumental analyses that characterise raw materials and technical practices, art historians can more confidently identify two works made by the same hand, or discern different stages in the creation or modification of an art piece. Associated to this change is also the growing quest for technical art history to be less concerned with the aggrandisement of individual artists (and their market value) and more with a humanistic, contextual understanding of art materials and practices (e.g. Ainsworth 2005; Hermens 2012). In this quest, technical art history could find much inspiration in archaeological studies of technologies.

Archaeology has a much stronger tradition of success at integrating empirical data in the study of humanistic questions related to past technological practice, agency, or human-environment interaction - to name but a few relevant areas. It is therefore surprising that relatively few studies of archaeological material culture have placed the focus on the individual, beneath the broader class of 'makers' or 'craftspeople' and their community-wide 'technical styles' (for possible reasons, see Thomas et al. 2009 ). A notable exception to this pattern might be the attribution work of Sir John Beazley (1956, 1963, 1971; Kurtz \& Beazley 1983) with Archaic and Classical black- and red-figure vase painting - but his approach, in line with that of Morelli, was much more art historical than archaeological, as is the more recent work on Cycladic marble figurines (Getz-Gentle 2001; GetzPreziosi 1987). Perhaps of more interest here is the work of Olivier (1967) identifying scribal hands in Linear B tablets - a study that would be superbly enhanced today by crossing this information with a materials science-based study of the clay substrate (e.g. Goren et al. 2011). A landmark publication was the collective The Individual in Prehistory (Hill \& Gunn 1977), which tried to formalise a method to identify individuals in different media but perhaps fell short of connecting with broader theoretical concerns (e.g. reviews by Bayard 1978; Kaplan 1980). Fifteen years later, Christine Morris tried to be more explicit about not only the method but also the questions that attribution studies in archaeology might help resolve, however her publication attracted equally mixed reviews (Morris 1993 and replies therein). More recently, Thomas et al. (2009) revisited the subject to usefully 
explore the challenges and potentials of identifying individuals for archaeologists of all theoretical persuasions. Although there are examples of individual-centred studies ranging from clay figures (e.g. Morris 1993) through pottery (e.g. Van Keuren 1999) and textiles (Marcus 2015) to carved glyphs (Van Stone 2001), it can be argued that only studies of knapped-stone artefacts have retained a sustained concern with individual knappers or 'moments in the past' (e.g. Cahen et al. 1979, Whittaker 1987; Pigeot 1990; Gamble \& Porr 2005; Watts 2013).

The identification of individual artisans allows finer grained studies of the organisation of workshops, or of the influence of paradigmatic makers in shaping schools and fashions (be it through direct transmission to apprentices, or through object copy by imitators). More generally, studying individual craftspersons or artists in their context provides insight into the complex dynamics that can take place between the individual agency, skill and freedom of an artisan, and the constraints imposed by limitations in human perception and skill, the learning context, resource availability, craft organisation, patron requests and broader sociocultural structures. As such, the potential of these types of studies is warranted (for further discussion, see especially Crown 2007; Hodder 2000; Knapp \& Van Dommelen 2008; Morris 1993; Plog 1977; Thomas et al. 2009; Watts 2013; White 2009; Whittaker 1987).

Analytical instruments enhance the sight of researchers looking for individuals in the artefacts they made, as they allow them to increase the resolution and analytical precision with which they can observe some traits, or even to record traits that would otherwise be unobservable. Yet, as far as we are aware, no-one has previously explored explicitly the role of materials science in studies of contextualised archaeological individuals. There are practical examples, however, where analyses have allowed such attributions, for example in Rehren and Kraus's (1999) identification of a shortlived and idiosyncratic metallurgical technique that was most likely the 'secret' of an individual artisan. With growing and deserved prominence, lan Freestone has championed a focus on 'the batch' - the output of an individual production event -, as an analytical category that may be identified through chemical analyses and allows higher-resolution insight into the organisation of production and consumption than usually afforded (Freestone et al. 2009a; 2009b; 2010; see also Blackman et al. 1993; Bezúr 2003). In a similar vein, an ongoing study of the Terracotta Army of China is employing morphometric and chemical traits of finished objects as proxies for small production cells working on a single, large commission of highly-standardised bronze weapons and ceramic warriors (Bevan et al. 2014; Li et al. 2014; Martinón-Torres et al. 2014; Yuan 2014). Even though the batches identified and discussed in these papers are likely to represent the work of relatively small groups rather than single individuals, they are increasingly showing the potential of research on craft production and consumption that disentangles the internal diversity of the 'production areas' or 'technological traditions' of more common approaches. Also worthy of mention is the work led by Izumi Shimada and his concept of 'nested contexts' in the study of archaeological technologies, which has revealed a so-called 'modular' organisation of artisans within which the work of individuals with idiosyncratic techniques and skills can be singled out (e.g. Shimada and Wagner 2007 and references therein).

The present paper explores science-based archaeological connoisseurship as an approach to archaeological material culture that takes advantage of analytical instrumentation to identify the work of individual artisans, with a view to addressing archaeological questions. It focuses on four assemblages of votive goldwork recovered in the Eastern Highlands of present-day Colombia. On the 
basis of their iconography, style and broad technological traits, as well as their depositional pattern, they can all be confidently assigned to the Muisca tradition or 'technological style'. Their analytical study confirms our previous suggestions about the manufacture and meaning of Muisca votive offerings, and allows us to refine previous observations based on their chemical composition. Moreover, through microscopic and chemical analyses, we identify technical gestures, material choices and skill levels that seem idiosyncratic of individual artisans. It thus becomes possible to characterise the structured variability that exists within the broader tradition, which is partly explained as resulting from sociocultural constraints (the 'commission' of specific ritual offerings, and the learning traditions) but also, most likely, from the motor habits, skill and artistic license afforded by each practitioner. In one case, we propose that the hand of a master and one or more apprentices may be identified behind a single offering. We conclude that, although many challenges remain, archaeological science methods make it increasingly possible to disentangle the socially construed components of a craft tradition from the individual agency, and encourage researchers to explore this approach in other areas.

\section{The Muisca and their goldwork}

The Muisca were a Chibcha-speaking group that inhabited the Eastern Highlands of Colombia when the Europeans encountered them in 1536 (Figure 1). Although relatively egalitarian, most Muisca villages had chiefs and priests who had some privileges but were also responsible for the welfare of their communities. They practiced agriculture, pottery-making, metalwork and textile production, salt and emerald mining. They exchanged their products for gold and beeswax for metalwork, as well as cotton, shells, feathers, and other commodities (Langebaek 1987a, 1995, 2005; Langebaek et al. 2011). Human sacrifices, votive offerings and psychotropic consumption occupied a central stage in religious rituals - activities in which metal artefacts played a key role (Lleras-Pérez 1999).

Muisca metalwork includes alloys covering the whole range of proportions between copper and argentiferous gold (Uribe-Villegas 2012; Uribe-Villegas \& Martinón-Torres 2012a, 2012b). Since gold parting and silver metallurgy were not known, the only way to adjust the silver content in the alloy was through dilution with copper or by selecting different gold nuggets based on their source or colour. Muisca metal objects fall under two broad functional categories: adornments (including crowns, nose-ornaments, ear-pendants, necklaces and breastplates, sometimes found as burial goods) and votive offerings. The latter are far more abundant. Votive offerings usually take the form of a group of small anthropomorphic figurines or tunjos, often contained in a ceramic vessel and accompanied by other metal objects representing scenes, animals, shafts or entheogen consumption trays, sometimes together with non-metallic materials such as emeralds, ceramic beads, snail shells or even colonial glass (Lleras-Pérez 1999; Uribe-Villegas 2012; Uribe Villegas et al. 2013).

Based on the iconographic, technical and stylistic study of metal objects, we have previously proposed that all the objects in a given offering were generally made in a single manufacturing event, at the same workshop and, often, with a single metal batch. In each case, the iconography is coherent among the objects, with many or all of them being related, for example, to entheogen consumption, caciques or rulers, war, birth or human sacrifice. This is consistent with ethnohistorical records indicating that votive assemblages were made on specific commission and offered soon after, seeking divine support for a well-defined need (Uribe-Villegas 2012; Uribe-Villegas \& 
Martinón-Torres 2012a; Uribe-Villegas et al. 2013). In addition, we noted that the objects were typically deposited in the offerings with very little cleaning or finishing work, often with unrepaired casting flashes or errors. On this basis, we have argued that the step of modelling of the wax, prior to making the mould for lost-wax and casting the metal, was as culturally important as the metal itself (Martinón-Torres \& Uribe-Villegas 2015). All of these would be shared elements of what we might call the Muisca technological tradition.

The current paper focuses on four of those offerings, which were subjected to more detailed analyses in order to verify the above propositions, and to identify specific traits within that shared tradition that might be indicative of individual artisans. We report observations on each of these assemblages before turning to a broader discussion that highlights underlying themes and their significance for further studies of prehistoric arts and crafts.

\section{Methods}

Bulk chemical analyses of major elements were necessary to characterise the range of alloys employed. These had to be non-invasive in order to preserve the integrity of the artefacts. Hence, all the metal objects were analysed at the Museo del Oro in Bogotá using Olympus Innov-X Delta Premium portable X-ray fluorescence spectrometers ( $\mathrm{pXRF}$ ), equipped with silicon drift detectors (SDD) and providing a typical resolution of 145-155 eV FWHM for 5.9 kV X-rays (on an AISI 316 standard). In all cases, the factory-built Alloy Plus method was employed, which uses a fundamental parameters algorithm for quantification. Analyses were performed at $40 \mathrm{kV}$ using the so-called Beam 1 , which includes a $2 \mathrm{~mm}$ Al filter in the X-ray path, for measurement times of 30-40 seconds and analytical areas of either 3 or $10 \mathrm{~mm}$ in diameter (see Supplementary S1). The results presented are average values for $\mathrm{Cu}, \mathrm{Ag}$ and $\mathrm{Au}$ of at least three repeat analyses per object, in percentage by weight. Although the manufacturer and set up are largely the same, three different instruments were employed in the course of this research - hereby labelled pXRF 2011 (for Carmen de Carupa, Tocancipá and Tenjo assemblages), pXRF 2012 and pXRF 2013 (both for Suba) after the year when the analyses were conducted. Thus it was important to not only monitor accuracy, but also to ensure that results from the various instruments are comparable. These determinations are reported in the Supplementary Material (Supplementary S1), together with further details of analytical and data processing protocols.

Selected objects from the four offerings were temporarily exported to Europe for further analyses by scanning electron microscopy (SEM) and laser ablation inductively coupled plasma mass spectrometry (LA-ICP-MS).

As detailed in section 5 , trace element analyses sought to confirm if objects suspected to derive from the same metal batch also shared the same geochemical signature. For this purpose, LA-ICP-MS was employed as a quasi-non-destructive technique (analytical craters are imperceptible to the naked eye) with established success in the field of ancient gold analysis. Analyses by LA-ICP-MS were performed at the Curt-Engelhorn Centre for Archaeometry under so-called 'wet-plasma conditions', as described in Kovacs et al. (2009). The laser was a Nd:YAG nanosecond laser operating at $213 \mathrm{~nm}$ (New Wave, LUV213 Nd:YAG Laser, VG Microprobe II). Optimisation of the ICP-MS and the laser ablation system followed the approach summarised in Kovacs et al. (2009), using house standards 
NA1 and NA2 as reference materials, and obtaining comparable precision and accuracy. All matrix elements were measured and taken into account for the calculation of the element concentrations. Depending on the objects, either line or spot ablation was used for data acquisition. When spot ablation was used, a pre-ablation was performed (ca. 15 pulses with a spotsize of $70 \mu \mathrm{m}$ ) to remove potential surface contaminations. Then data acquisition started with the measurement of ca. $40 \mathrm{~s}$ of the blank followed by approximately 80 s of signal acquisition from a single crater ablation (spotsize $50 \mu \mathrm{m}$; frequency $5 \mathrm{~Hz}$ ). Line ablation was performed in the same manner and the ablated lines usually were $300 \mu \mathrm{m}$ long ( $5 \mathrm{~Hz}$ and ca. $4-5 \mu \mathrm{m} / \mathrm{s}$ scan speed with a width of $50 \mu \mathrm{m})$. Line ablation was the mode typically employed, and results from line scans are reported in the main dataset for the Carmen de Carupa, Tocancipá and Suba assemblages. For the Tenjo offering, spot ablations were used in order to compare the composition between surface and cores (the latter, through existing dents and cracks), and these are the results reported. However, some objects were analysed using both line and spot scans to assess data reproducibility between ablation modes (see Supplementary S2).

A comparison between pXRF and LA-ICP-MS results for the major elements shows an overall agreement between both datasets, but also some unsystematic divergence between data points, sometimes exceeding $10 \%$ relative (Supplementary S2). This disparity can be explained with reference to the different sampling methods for each technique as well as the heterogeneity of the artefacts themselves. First, while the PXRF analyses a relatively wide surface area $(\varnothing=3-10 \mathrm{~mm})$, the LA system ablades only a very small spot $(\varnothing=50 \mu \mathrm{m}$, or $0.05 \mathrm{~mm})$ or thin line of a few tens of $\mu \mathrm{m}$ in length, from just below the surface. Thus, while the pXRF analytical area is likely to be more representative of the bulk if no surface treatment is present, with LA-ICP-MS there is a higher risk to analyse individual phases in the metal that are enriched/depleted in particular elements. Considering the heavy alloys and slow cooling of the artefacts analysed, metal segregation is considerable. This is evidenced, for example, in repeat analyses of artefacts 033878 and 033880 , which were clearly cast together in a single pour (see below, 4.1). In spite of their very small size (less than $2 \mathrm{~g}$ in total weight), LA-ICP-MS results for these scatter considerably (43-49\% Cu, 8-10\% $\mathrm{Ag}, 43-49 \% \mathrm{Au}$ ), whereas pXRF results appear more consistent $(47.4-48.6 \% \mathrm{Cu}, 9.4-9.8 \% \mathrm{Ag}, 42.0$ $42.8 \% \mathrm{Au}$ ). The widest disparity between results from both techniques was found in the analyses of the Tenjo objects, which, as discussed below (Section 4.3), were corroded and showed clear surface/core differences.

For the sake of consistency, unless otherwise noted, we will be discussing pXRF values for the major elements $(\mathrm{Cu}, \mathrm{Ag}, \mathrm{Au})$ and LA-ICP-MS results for minor and trace elements, but the full datasets are included in relevant tables (See also Supplementary Material).

Analyses by SEM focused on the texture and micromorphology of the objects, with a view to identify manufacturing traits as well as possible remainders of mould materials. The instrument employed was a Hitachi S-3400 at the UCL Institute of Archaeology, operating in high vacuum and at accelerating voltages between 10 and $20 \mathrm{kV}$. Imaging was obtained using both a secondary electron detector (SE) and a large area solid-state backscattered electron detector (BSE) with five radial detector segments that can be turned on and off to create topographic detail while minimising the visual effects of sample changing or surface dirt (see Li et al. 2012 for discussion of a similar approach). 
It is important to note that, as claimed previously and substantiated in this paper, all the objects where cast directly by the lost-wax method, with no soldering or casting-on, and with very limited finishing work post-casting. Hence, many of our observations on the metal artefacts pertain to the artisans' gestures and skills when modelling the wax and creating the mould around it, rather than to artisanal work performed with solid metals.

\section{Muisca offerings: iconography, material selection and artisanal practice}

\subsection{Carmen de Carupa: basket men}

This very small offering is made up of three miniature tumbaga figures (O33878 to O33880), measuring between 0.9 and $1.4 \mathrm{~cm}$ in height, recovered at vereda Charquira, in the municipality of Carmen de Carupa, Cundinamarca. All three of them represent the same human character, sitting with their knees embraced close to their chest (Figure 2). This posture is often referred to as 'basket man' (hombre canasto in Spanish), as this is the name employed among some Amazonian communities (Torres 1985: 56). 'Basket men' are relatively common in Muisca assemblages, with over 100 held in the Gold Museum collection, even if showing different styles. In some contexts, such as this one but also the cache of 40 likely female tunjos associated to a post-contact child mummy in Gachantivá, Boyacá (033908 to 033947), this type of character makes up all the items in the offering.

In the case of the Carmen de Carupa offering, they all display a characteristic schematic style. Their overall shape is almost identical, but some distinctive features indicate that each figure represents a different individual: for example, the trapezoidal, tridimensional crown and the small tree-like feature at the shoulder of one of them (033880), which might constitute the top end of a shaft; or the presence of nipples in another (033879). The microanalytical study shows a very consistent set of manufacturing traits in the waxwork: in each figure, the body was cut out of a wax sheet in the shape of an oval or rectangle for the head, and a trapecium for the torso. The arms were made with two wax coils that were adhered to the shoulders and project forwards to form a semicircle on the front; two further coils, bent and attached at the base of the torso, form the legs. For the eyes, the artisan pressed two wax threads transversally to the face and cut them together with a sharp tool, as evidenced in the cutmarks. The mouth was made in the same way, whereas the nose was made with a vertical coil that overlaps with eyes and mouth. Two of the figures show three more transversal coils on the top part of the head, creating a form of textile headdress, whereas the third one wears a crown (Figure 2).

An important feature is the small subrectangular sheet attached to the back of the head in two figures (033878 and 033879), which shows an irregular, broken edge. In one of these objects (033878), the shape of this ruptured edge fits perfectly with the lower edge of another figure (033880), revealing beyond doubt that after modelling both figures in wax, the artisan joined them together before forming a single casting mould around them. Both figures were cast together in a single pour and subsequently broken apart quite crudely - a form of 'chained casting' for which we only know another example in Colombia (Uribe-Villegas et al. 2013: 75). This finding reinforces the interpretation of this group as the outcome of a single production event and, quite likely, a single artisan. It also raises the possibility that a fourth figure might have existed, whose base would fit the ruptured edge on the head of figure 033879 (Figures 2-3). 
The small size of the figures and the thinness of the wax coils employed $(<500 \mu \mathrm{m})$ denote the remarkable skill of this artisan, probably an experienced individual. The casting of such small, intricate objects would have required the mould to be preheated in order to prevent the metal from freezing before taking up all the details of the mould. The large dendrites that can be observed on the surface of all the figures are consistent with a slow solidification process in preheated moulds. Another interesting aspect is the presence of a fine-grained, black, carbonaceous material adhering to the surfaces, particularly in the crevices that are left in the joints between metal coils. This material is interpreted as remains of the moulding material originally applied to the wax model and never thoroughly cleaned out of the metal objects post casting (Figure 3 ).

Chemical analyses indicate that all three figures are made of a single alloy, as they were likely cast from a single crucible - thus falling in our 'Type 1' or 'mono-alloy' category (Uribe-Villegas 2012; Uribe-Villegas \& Martinón-Torres 2012a). This is a tumbaga with approximately $43 \%$ gold, $9 \%$ silver and $48 \%$ copper - an alloy that would result of a 1:1 combination of copper with argentiferous gold (gold with $18 \%$ silver, calculated as \%Ag/[Ag+Au]) (Table 1; Figure 4). The relatively high silver and copper content explains the pinkish colour of the objects.

\subsection{Tocancipá: the cacique enclosure}

Recovered at Vereda Canavita, municipality of Tocancipá, Cundinamarca, this is one of the most complex offerings in the Gold Museum collection, given its iconography and the diversity of exotic materials collected, which suggest it must have been commissioned by a high-status individual. The offering container is a ceramic vessel (C13488) shaped like an oval hut or enclosure, with two anthropomorphic figures at the entrance. The internal space is structured by several lines of fencing supported by poles, as well as various cavities impressed in the clay. Five concave ceramic plates were recovered as well, one of which served as a lid. The metal elements in the offering are four anthropomorphic figurines of gold (033895 to 033898), two small planoconvex casting ingots (known as tejuelos), a microscopic metal spherule, and two natural nuggets of gold (O33898a-d). In addition, 37 emerald crystals (E00018), eight fragments of glass rods (V00017) and hundreds of tiny stone beads (C13499) were recovered. A small stone slab (L03492) and several bone fragments (H00333) complete the assemblage (Figure S5).

The shape of the offering vessel depicts a well-known iconographic motif, typically referred to as the 'cacique enclosure'. Such motifs typically show a large 'chief' at the centre (absent here) surrounded by the enclosure, with two sacrificial posts at the entrance. Morphologically, the Tocancipá ceramic vessel bears an exceptional resemblance to a gold 'cacique enclosure' recovered in Pasca and now held at the Ethnographic Museum of Berlin (Henderson \& Ostler 2005; Uribe-Villegas et al. 2013: 29). A noteworthy aspect is the presence of glass (Therrien 2001). Chemical analyses of a sample (Supplementary S3) showed it to be of the high-lime low-alkali (HLLA) type, a type of glass abundantly produced in Europe from the Late Middle Ages (e.g. Dungworth \& Loaring 2009; KunickiGoldfinger et al. 2009; Schalm et al. 2007). Although its composition differs from glasses dated to after the $17^{\text {th }}$ century, it is currently not possible to assign it to any chronological or geographic bracket with more resolution. In any case, this offering thus illustrates the endurance of indigenous ritual practices in the face of prosecution, but also their transformation through the recontextualisation of exogenous materials (cf. Martinón-Torres et al. 2012 for similar practices in 
colonial Cuba). In particular, the formal and visual similarities between the 'traditional', indigenous emerald and 'new', exogenous glass in the offering may be suggestive of one material replacing the other. The metal elements, incorporating raw materials as well as intermediate (ingots) and finished items, convey an idea of 'transformation' that is often documented in Pre-Columbian goldwork generally (Falchetti 2003; Reichel-Dolmatoff 1981) and Muisca offerings in particular (MartinónTorres \& Uribe-Villegas 2015).

As in the previous offering, the four tunjos show human figures in a schematic style, sharing several features: an elongated, compact and somewhat crude figure with rounded, soft edges; prominent head and ears; flexed legs, and arms folded towards the chest ending in large, open hands (Figure 5). All figures wear hats - two of them plain (033896, 033897), and two covered by a spiralling coil (033894, 033895). At the same time, specific attributes show differences among characters: for example, the figures with plain hats are smaller, perhaps denoting a lower status, and the largest one (033894) wears distinctive ear spools.

Technological analyses show that the wax models were constructed in the same way for all the figures (Figures 6 and S6): an oval sheet forms the head, which was superimposed to a trapezoidal sheet that delineates the body; interestingly, this artisan reinforced this joint on the back in all cases with one or two wax coils that functioned as staples; the lower body part was then stuck to a subcylindrical element that served as sprue cup, and where the legs rest. Further technical details coincide among the figures: for example, the eyes are made of thin threads shaped like the letter ' $C$ ' and open to the sides; in many cases, these were placed somewhat carelessly on top of the ears; the mouth is also a ' $C$ ', open to the left; the nose was made of a vertical coil folded onto itself, and the ears were constructed using concentric, semicircular coils. All hands show three fingers, whereas feet are only subtly outlined in one of the figures. A peculiar characteristic reinforcing the interpretation of this group as the result of a single production event is the smoothening or softening of the wax coils prior to moulding and casting, which results in faded contours. It appears that, prior to covering with the charcoal powder and clay used for moulding, the wax models were gently heated, perhaps by handling.

Also the casting process shows coincidences within the set, although these are shared with many more tunjos in other assemblages. As common in this type of objects, the casting clearly took place with the figures up-side-down. While the figure surfaces generally show the dendritic texture characteristic of slow-cooled alloys, the tip at the feet of the figures is perfectly rounded, shinier and finer-textured, reflecting the metal surface tension and the relatively faster cooling of the metal at the mould opening, where it probably was in contact with air. It is important to emphasise that each tunjo was cast complete in a single pour, without any evidence of casting-on or soldering of separate parts. In this sense, even if some metal filaments can be observed connecting metal coils such as those forming the headdress, we do not interpret these as remains of high-temperature soldering; rather, they are simply reflecting the flow of metal by capillary action between two metal parts that were in contact during the pouring and solidification (Figure 7). The smooth, rounded appearance of the 'frozen' surface tension at the feet of the tunjos is also noticeable in the 'tejuelos' (Figure S7), in stark contrast with the more rugged, irregular appearance of the natural gold nuggets (Figure S8).

The major element composition reveals three chemical groups, corresponding to the three typological groups, based on different levels of copper (Table 2; Figure 8): high in the tunjos, 
intermediate in the tejuelos and the spherule, and virtually absent in the gold nuggets. The tunjos were made of an alloy with an average composition of $53 \%$ gold, $24 \%$ silver and $23 \%$ copper, corresponding with their whitish pink colour. The casting ingots are very similar to each other, with only $17 \%$ silver and $12 \%$ copper, whereas the spherule has marginally higher $\mathrm{Ag} / \mathrm{Au}$ ratio. Turning to the nuggets, they are similar in their lack of copper but show widely differing silver levels: 16 and $36 \%$, respectively - the latter at the upper end of the known ranges for Colombia (cf. Uribe-Villegas 2012; Uribe-Villegas \& Martinón-Torres 2012b). The presence of two gold nuggets with such different silver levels is quite significant, as it demonstrates that the artisan had access to argentiferous gold with different compositions. Even if all the gold available to them could derive from the same source (but see below, section 5), they might still be able to discriminate among natural alloys based on their colour. Bearing this in mind, the plot of the tunjos compositions in the ternary diagram illustrates another interesting detail: they all have similar copper levels, but variable silver/gold ratios. It therefore seems that each tunjo could have been cast with a separate batch of metal: in all cases, the alloy would be roughly a combination of one part of copper to three parts of argentiferous gold, but the latter would have a different silver content in each case. We cannot tell whether these compositional variations would have been intentional, i.e. the result of selecting different types of gold for each artefact.

\subsection{Tenjo: a burnt offering}

Five metal objects (O33809 to O33813) and an emerald (E00015) make up this offering, found at a depth of $50 \mathrm{~cm}$ at vereda Chince, municipality of Tenjo, Cundinamarca. The finders reported that the items were found inside a cylindrical ceramic vessel, but this never reached the Museum. The metal artefacts include three standing males (O33809 to 022811) and two staffs with ornitomorphic representations (033812 and 033813). The human figures show similar traits, but also some differences in their size and number of attributes are notable: the smallest one (033810) carries a dart thrower in one hand and a lime flask in the other; the second one in size (033809) is quite similar but also carries a dart together with the thrower, as well as a small pouch hanging from the belt; the largest figure (033811) wears a more elaborate headdress, which probably had pendants (now lost), and also carries a lime flask and a pouch (Figure 9).

Again, the iconography and characters in this offering are documented elsewhere in Muisca goldwork, while also showing some individual peculiarities that make this assemblage unique. For example, the Gutiérrez offering, described elsewhere (Uribe-Villegas \& Martinón-Torres 2012a; Uribe-Villegas et al. 2013: 74-77), although in a clearly different artisanal style, also includes three warriors of different sizes with dart throwers and lime flasks; in the Tenjo offering, however, the largest figure is not armed. Staffs with bird decorations are absent in the Gutierrez offering but present in Suba (see section 4.4), where warriors are present together with numerous other characters that are absent in Tenjo. Emeralds are present in numerous offerings (Lleras-Pérez 1999; Uribe-Villegas et al. 2013). Clearly, the different elements of the Muisca material and iconographic repertoire are combined in numerous ways to convey different meanings - each offering tells a different story.

Manufacturing traits show the characteristic technique and skill of an artisan who appears to have been very thorough and experienced (Figures 10 and S9): in the spiral ears, the throwers, the hands 
and ears, for example, one can observe a particular concern with symmetry using wax coils of very uniform thickness (even if some errors are noticed, e.g. in the right foot of 033810 where two semicircles appear superimposed rather than concentric). While the construction of the body overall, legs, head etc. show remarkable similarities, the larger figure (033811) shows peculiarities, such as the closed ovals used for eyes and mouth (as opposed to open ' $C$ 's in the others), which may relate to the type of character represented.

Under relatively low magnification, the figure surfaces show the dendritic texture and lack of soldering that is typical of the Muisca tradition. Similarly, remainders of charcoal dust used to make the mould around the wax models are preserved in some clefts. However, when analysed in more detail, objects in the Tenjo offering also show some atypical features, both in their visual appearance and in their texture and composition. Two of them (033811 and 0338813) show a whitish, matt colouration with some very dark zones; figure 033811 is extremely corroded and brittle - in fact, the head was broken off prior to recovery, with severe corrosion of the fractured edges. All the objects display some black soot strongly adhered to the surface, and clearly different from the charcoal dust described above (Figure 9). These features indicate that the offering was exposed to fire after it was cast.

Small fractures on the surface of 033811 allowed us to document the black, corroded appearance of the metal substrate beneath the superficial layer (Figure 11). Both SEM-EDS (not reported) and LAICP-MS spot analyses (Supplementary S2) confirmed that copper levels are slightly lower at the surface, which is richer in gold. Under higher magnification, this surface shows a very porous texture, consistent with the loss of copper through oxidation (Figure 12). All of these features are consistent with a process of depletion gilding - a technique widely documented in America and elsewhere, but virtually absent among the Muisca (cf. e.g. Bray 1993). We believe that, rather than an intentional practice, the surface gilding is just a side-effect of exposure to fire.

In sum, the surface oxidation and traces of uncleaned soot on the surface indicate that the offering was burned after manufacture, and never cleaned after that. It is tempting to think of the burning or heating as part of the Muisca cultural practices associated to votive offerings - as indeed suggested in colonial documents (Londoño 1989: 99). However, burning of agricultural fields may have taken place in the Eastern Highlands of Colombia since Prehispanic times, hence we cannot rule out the possibility of an accidental burning after deposition (Boada Rivas 2006: 140).

Considering the corroded state, surface dirt and compositional differences between surface and core of these objects, we should bear in mind a considerable sampling uncertainty when interpreting the pXRF results. This may also explain the slight differences between two XRF datasets available for some of the objects (Table 3 ). Broadly, the objects show a range of tumbaga compositions with relatively uniform gold/silver ratios, thus consistent with a single batch of argentiferous gold diluted with variable amounts of copper, and assigning them to our offerings Type 2 or 'poly-alloy' (UribeVillegas 2012; Uribe-Villegas \& Martinón-Torres 2012a). The argentiferous gold employed would have had approximately $23 \%$ silver (Figure 13 ). 


\subsection{Suba: master and apprentice at work?}

This offering contains one of the largest numbers of gold-alloy objects, totalling 34 (O33278 to 033311) (Figure 14). It was found inside a ceramic container (not preserved) at vereda Buenos Aires, municipality of Suba, in Bogotá, D. C. Besides its sheer size, this offering is remarkable in its iconographic complexity. It is composed of a relatively large gold ingot (033310) and 33 figures that display a wide range of motifs, some of them repeated and thus revealing recurrent themes: out of 25 human figures, 17 are males ${ }^{1}$, three are females and five are babies of both sexes tied to their carrying cots. Of the adult male figures, eleven wear headdresses with losenges, and four wear plain crowns; nine carry dart throwers, with five of these also carrying a shield, and seven a staff with a bird, or a bird on their shoulder; three show pouches, four a cylindrical pendant at the neck and another four a spiral pendant. The three female figures show a tight hat; two of them carry babies. Additionally, there are four zoomorphic figures: two birds (one clawing a possible snake), a snail (with spires) and a quadruped with whiskers, perhaps a feline. The gold assemblage is completed by a stretched animal skin (apparently of a feline too), a dart thrower, a short staff with bird decoration, and a small globular pouch or basket (Figure 14; Supplementary S4).

It is hard to disentangle the actual purpose or meaning of an offering that seemingly combines so many themes. Some of the recurrent images are those of heavily adorned warriors, mothers carrying babies and children in their cots, as well as birds. Those repetitions speak of some internal coherence that must have been understood by the Muisca. A tentative story connecting these elements would be that of children sacrifices - a practice documented in historical sources (Simón 1981: III, 393) -, but of course we cannot prove such an interpretation without a fuller understanding of Muisca material culture and religious behaviour.

Manufacturing traits also reveal a more complex universe. In contrast to the individual artisans producing each of the offerings discussed above, we propose that at least two artisans were involved in the making of the larger Suba offering. These are discernible in both their personal styles and the dexterity shown in the modelling of the wax. The first artisan stands out because of a finer and more skilled use of the wax, sometimes employing extremely thin threads of less than half a millimetre in thickness, and creating very small items such as the dart throwers, birds or the pouches carried by the males (Figures 15-16 and S10-14). While the work of this individual shows a personal preference (and ability) for small, highly detailed items, it is also more closely aligned with the broader canons of Muisca goldwork for the representation of human figures: the eyes and mouth made with flattened ' $C$ 's, the spiral ears and the overal shape and proportions are typical and found in hundreds of Muisca tunjos in other assemblages, for example in Tenjo (see 4.3 and discussion in 6.2).

As for the casting, the objects in this group show the large dendrites that characterise the slowcooled Muisca artefacts, but errors and unrepaired imperfections are relatively frequent. Several items (e.g. O33296, 033297, 033302, 033303; Figure 16) show gaps caused by an imperfect flow of the metal, as well as small voids that may have been caused by trapped gas - perhaps because there were not enough vents in the mould; others (e.g. 033294; Figure 15) show casting flashes in areas

\footnotetext{
${ }^{1}$ Sex allocation was based on the presence of genitalia or by attributes associated to a given sex in the same offering. We should therefore acknowledge that we are conflating biological sex with gender, and it thus remains possible, for example, that some of the 'male warriors' without genitalia actually are women.
} 
where the mould cracked during the pour. In one case (033293; Figure S11), the casting is so flawed that the artefact was rendered almost unrecogniseable. As typical of Muisca votive goldwork, these errors are not repaired, and the items are deposited in the offering with relatively limited cleaning post-casting (Figures 15-16 and S10-14).

A further feature worth highlighting is the frequent occurrence of small globules of metal which are often located between the metal threads and the flat plaque that functions as a base for the figures, but which also occur scattered on the back of several Suba tunjos. They are occasionally documented in the Carupa and Tenjo offerings too, but they are particularly conspicuous in Suba. Their frequent location in joints initially led us to think that they might constitute remainders of small balls of wax used to facilitate the attachment between wax parts during construction. However, it is perhaps more likely that some or all of these globules are simply indications of the former presence of voids in the mould, which were subsequently filled with metal. Their higher frequency at joints would simply reflect the higher likelihood of mould imperfections in these narrow areas, where air bubbles in the moulding material could remain more easily trapped by surface tension. Their higher occurrence at Suba would speak of consistent moulding practices, either in the material employed or in the way it was applied to the wax models.

Turning to the second Suba artisan(s?), the waxwork is less careful and the figures somewhat cruder and heavier, with wax coils of uneven thickness, and sometimes flattened by the pressure rather than circular in section - an heterogeneity that makes it possible that this group is the output of more than one person. In some cases, the design is not so closely aligned with Muisca conventions: for example, arms are not always flexed with the hands adhered to the chest forming a ' $W$ '. Furthermore, there is evidence of some errors that were repaired with limited skill: for example, one of the pendants dangling from the headdress in figure 033278 is hanging from a wire crudely tied through a hole in the crown, as opposed to the typical arrangement hanging from loops; another artefact (033285) shows evidence of hammering, cutting and perforating in the lower part to expand and open up the space typically present between the legs, probably because some casting problem led to this part being atypically short (Figure 17).

These marked differences raise the possibility that we may be witnessing the work of a master artisan and one or more apprentices. The master would have produced the largest number of items (at least 13 assigned to this group, possibly up to 20), including all the male figures with dart throwers and shaft, as well as most of the female figures and delicate items such as the dart thrower and the possible pouch. The more heterogeneous 'apprentice' group comprises seven items including all the male figures with dart throwers and shield. Babies in cots are present in both groups (Supplementary S4). The identification of several artisans working in parallel on a single offering is unusual, and it may have been triggered by the larger than usual size of the assemblage. This observation reinforces the idea that the offering would have constituted a single commission for a particular purpose and deadline, which would have required the intensification of the work. Casting imperfections and the metal blebs described above are frequent in many objects in both groups, which would suggest the use of similar moulding materials, or perhaps a single artisan preparing the moulds on wax models manufactured by different artisans. We have made a similar argument for the offering associated to the famous Muisca raft, whose exceptional complexity could also have demanded more than one artisan (Uribe-Villegas at al. in preparation). 
Chemical analyses of the Suba items reveal a remarkable variability, with copper levels ranging from 0.5 to $28 \%$, and hence making this a 'poly-alloy' or 'type 2' offering (Table 4; Figure 18). The result is a spectrum of colours that scatter from golden to red hues, particularly in the objects assigned to the 'master'. Values for \%Ag/(Ag+Au) typically point to the use of argentiferous gold with silver levels around $16 \%$, which is comparable to typical values for Muisca goldwork (Uribe-Villegas \& MartinónTorres 2012a, 2012b; Uribe-Villegas et al. 2013). However, extreme values of $13 \%$ and $25 \%$ may indicate, as in Tocancipá, that goldsmiths deliberately maximised the range of alloys employed not only by adding variable amounts of copper, but also by selecting different gold nuggets by their colour.

\section{Confirming metal batches: trace element analysis}

Trace element analyses by LA-ICP-MS sought to validate our proposition, based on major element analyses, that each offering was the product of a single metal batch (Uribe-Villegas 2012; UribeVillegas \& Martinón-Torres 2012a). This aim was especially challenging, given that we know very little about the actual metal sources employed by the Muisca. It is generally assumed that metals from the same sources were used by all, in every case obtained by trade: namely argentiferous gold from the Magdalena valley, and copper most likely from the districts of Cundinamarca or Boyacá (but see Uribe-Villegas 2012 for slight North-South differences in tunjo compositions). If this assumption is correct, trace element patterns could predictably be the same for all offerings, with little scope for discrimination between batches. However, we wanted to test if the particular combination of copper and argentiferous gold used for individual offerings might be reflected in specific trace element signatures.

The results largely validate our prediction (Table 5; Supplementary S5). The plot of the principal component analysis of a normalised subcomposition of trace elements shows the tunjos from each offering forming relatively tight clusters, and thus confirms that the geochemical signature for each figure tends to be quite similar to those of other figures in the same offering (Figure 19).

We hoped that correlations between major and trace elements, and relative proportions among the latter, could allow us to discern the traces associated to each major alloying constituent, i.e. argentiferous silver and gold. For large poly-alloy offerings such as that of Suba, with widely variable proportions of copper and gold, we expected traces of platinum group elements (PGE) to increase with gold content, and other elements such as $\mathrm{Ni}, \mathrm{Sb}$ or $\mathrm{Bi}$ to increase with copper levels. Such correlations, however, were not found in the dataset. Our predicted pattern may have been obscured by metal partition during segregation upon cooling, and thus LA samples not being fully representative of the bulk. For example, figures 033878 and 033880 from Carmen de Carupa, which were cast together (see above), appear the furthest apart within the Carupa group in the principal component space.

Finally, trace element analyses of the Tocancipá assemblage agree with pXRF results in identifying three chemical groups that correspond, respectively, to tunjos, tejuelos and natural nuggets - in addition to the small spherule that forms an outlier (Supplementary S5). It should be noted, however, that the artificial copper-rich alloys in this assemblage yielded higher PGE values than the natural nuggets (Table 5). Assuming that these results are representative, they would indicate that 
the high-PGE gold used to make alloys was from a different source - or, at least, a different batch from that offered in the natural state. This is in addition to the different $\mathrm{Ag} / \mathrm{Au}$ ratios noted for the tunjos (see above, section 4.3), which were also indicative of slightly different batches of gold.

\section{Discussion}

\subsection{The Muisca technological tradition: implications and challenges}

The stylistic, chemical and microscopic analysis of four Muisca votive assemblages allows us to confirm and refine some of our previous hypotheses with regards to this technological tradition, and to propose some pointers for future work in South American metalwork and beyond. First, we confirm the suggestion that each offering was made in a single manufacturing event, using a limited and coherent set of materials, techniques and iconographic motifs. The detailed study of manufacturing traits under the microscope indicates that, generally, a single artisan was involved in the making of all the items in a given offering. The unusually large Suba offering would seem an exception, with at least two artisans involved with different skill levels, possibly a master and one or more apprentices.

Chemical data are also consistent with our suggestion that a restricted range of metal sources, possibly single batches of argentiferous gold and copper, was used for each offering. An exception to this rule appears in the Tocancipá offering, where two gold nuggets were included that seem geochemically different from the main figures. Conversely, the single-source pattern applies even to poly-alloy offerings such as those of Suba and Tenjo, where gold and copper were combined in variable proportions to create a range of metal compositions. Given the very broad range of alloy compositions recorded in the Suba offering and others (cf. Uribe-Villegas 2012; Uribe-Villegas \& Martinón-Torres 2012b), it seems unlikely that this pattern is the result of carelessness in alloy selection: rather, we believe that the context and purpose of these specific offerings required the use of a range of alloys, all of them involving both copper and (argentiferous) gold. While these variable compositions altogether result in a noticeable spectrum of colours, we do not believe that colour was the main concern: the seemingly unfinished, dirty state of many of these objects, together with the fact that they were often wrapped in cotton (Falchetti 2003; Londoño 1989; Reichel-Dolmatoff 1981) and possibly burnt and hidden rather than displayed, argues against visual appearance as a foremost parameter for those who commissioned and made them (see also Martinón-Torres \& Uribe-Villegas 2015). This is in contrast with other approaches to American metalwork, which have emphasised the critical role of dimensions such as brilliance (Saunders 2011) or colour (e.g. Hosler 1994) - if anything, Muisca metalwork may have materialised more abstract 'colour energies', as described in Amazonian ethnographic contexts (Reichel-Dolmatoff 1978, 1981).

These peculiar compositional patterns should act as a cautionary tale for archaeological scientists elsewhere. Archaeometallurgists regularly employ analytical data from metal and other artefacts to seek compositional clusters with statistical significance, before then trying to explain the archaeological significance of such groupings. However, statistics should remain just an aid, and data structures with archaeological meaning may not always be best revealed using established statistical procedures (Baxter \& Freestone 2006). A scatter in the major element compositions of an assemblage may lead to speculation about a variety of sources or chronologies, lack of standardisation, or experimentation. However, our study of Muisca metalwork has evidenced the 
presence of chemical scatters of artefacts that clearly followed a pattern and had archaeological meaning as the result of deliberate choices made in a single moment. These would not be easily identified in a large database if explored using modern heuristic typologies and reference frameworks, not least because the items in a given contextual group were sometimes deliberately made to have different compositions.

Furthermore, our research highlights the crucial role of wax, and wax-modelling, in the production of lost-wax metalwork. The care and dexterity displayed in the use of wax, often contrasting with the casting flaws and unfinished state of many objects, argues for the cultural and technical importance of this often overlooked element of the chaine opératoire. Indeed, as we have argued elsewhere, the symbolic importance of wax, rather than practical concerns with efficiency, may be the ultimate reason behind the discovery and endurance of lost-wax casting in some South American regions - a hypothesis to be tested in America and elsewhere (Martinón-Torres \& Uribe-Villegas 2015). It is also apparent that the raw materials and manufacturing process had to be materialised in the offering themselves, as manifest not only in the inclusion of natural minerals and nuggets or intermediate products such as ingots, but also in the casting funnels, feeders and mould remains left in some tunjos.

\subsection{The Muisca artisan: implications and challenges}

All in all, with reference to previous studies and the present work, we can list some common traits that define the Muisca votive technological tradition or 'technical style'. Collectively, they form a set of constraints that rendered Muisca offerings acceptable and understandable in their specific sociocultural context. Individually, they may serve as 'memes' that could be traced in comparative and evolutionary studies of technology and knowledge transmission (cf. Shennan 2013). With very few exceptions, all the metalwork in Muisca votive offerings was: a) made by the lost-wax method, b) in a single manufacturing event, c) with a limited set of metal sources, always including both argentiferous gold and copper, d) with each artefact cast in a single pour, e) left in an 'unfinished' state, with limited post-casting work, e) not made to be displayed, and f) deposited soon after their manufacture. A further shared element is that the materials and iconography of each component made sense in combination: collectively, each offering narrated a story.

Within this broad set of constraints, the study of Muisca offerings also allows us to identify individual agency at play. In the first instance, the person or group commissioning each assemblage probably imposed further rules specific to each assemblage, such as the particular motifs or iconography, as well as the context of deposition - most likely depending on the specific meaning and purpose of the propitiatory offering (cf. Simón 1981 [1527]). It is possible that the patron also dictated the actual materials to be employed, including the alloy or range of alloys, also depending on their particular nature of the favours being sought. Given our limited knowledge of the social status of goldsmiths and artisans generally, it is hard to conjecture whether these individuals would have been involved in negotiating those symbolic and material aspects.

Lastly, beneath the relatively tight constraints imposed by tradition and commission, individual artisans displayed their skill, motor habits, artistic license and personal preferences in the actual materialisation of the offering. These are noticeable in aspects such as the thickness and evenness of 
the wax coils employed to model their figures, the techniques employed to attach several wax parts together, or the individual modelling of elements such as eyes, ears, hands or feet. Besides individual working habits in the modelling of wax, remnants of the moulding and casting stages also speak of idiosyncratic practices. In fact, more detailed analyses of mould remains may provide additional strands of evidence to identify individual practice within and between offerings (cf. Mugnaini et al. 2014 for a comparable study on casting cores of Renaissance statues)

We must acknowledge important challenges (and associated opportunities) for this study and others of its kind. The first one derives from the difficulties in discriminating between what Whittaker (1987) called "attributes of execution" and "attributes of form". Attributes of execution are the result of largely unconscious, motor habits that can be highly idiosyncratic and thus, in principle, the foremost traits we should define when searching for individual artisans. In this category we could include the peculiar way in which the Tocancipá artisan stapled together the various wax components, or the exceptional thinness and regularity of the coils employed by the 'master' of Suba. Attributes of form are evidence for the consciously controlled aspects of the craft, and may therefore reflect broader social codes rather than individual agency (what we usually call 'style'). For example, in a great number of votive offerings, relative sizes seem to correlate with the rank of the person represented (the cacique always being the largest), and the overall width of the figures tapers from shoulders to feet. These are unlikely to be the decisions of a single individual. An additional factor reflected in material culture is skill, which may to some extent be learned and, as such, change over time. While variable skill levels may help us discriminate between individuals in single production events, as in the case of Suba, skill development over time may also blur the differences between individuals (see Thomas et al. 2009 for further discussion).

There are some traits in the objects that cannot be easily assigned to either execution or style categories. As a significant case in point, we would like to draw attention to the peculiar spiral ears exhibited by many tunjos, including those of Tenjo and Suba above, but many more (Figure 20). According to the Morellian method, ears are accessory components whose depictions might expose the unconscious habits of an artist. In the early days of connoisseurship, Berenson (1902: 130) noted that the ears are "more characteristic [of an individual painter], indeed, than any other detail of the human figure", (ibid. 132-2) "(a) as they are not vehicles of expression; b) as they do not attract attention; (c) as they are not controlled by fashion; (d) as they allow the formation of habit in their execution". When writing about these and other attributes he warned, however, that "the followers and copyists of these masters share the same peculiarities, which can therefore serve only as indications of school, and not of the individual artist" (ibid. 132).

The spiral ears are so frequently documented in tunjos that they are extremely unlikely to have been modelled by a single artisan, not least since some date several centuries apart. At the same time, not all the tunjo ears show this shape, which suggests that the spiral ears were not part of a Muisca-wide shared canon or style. As a hypothesis, we propose that the spiral ear may originally derive from a single artisan, but that this trait was replicated by others, quite possibly by direct knowledge transmission. If we bear in mind the small size of these ears, and especially the fact that the objects were deposited soon after manufacture, the window of opportunity to learn how to imitate these ears would have been small, unless one saw the manufacturer during the making. If our hypothesis is true, then the widespread occurrence of this ear type across the eastern highlands of Colombia would be a strong indication that the number of artisans was relatively small, that they were 
specialists who taught apprentices, and that they travelled with their skills to cater for potential commissions. The small number of specialists and the highly specialised skills required could also account for the technological conservatism witnessed over the centuries of the Muisca goldsmithing tradition (cf. Roux 2010).

A second challenge for attribution studies in archaeology is posed by objects with complex sequences of manufacture and modification, which may have involved different individuals at various stages. For the Muisca votive objects, there are strong indications that their life-histories were relatively short before deposition, but one can still ask whether the wax sculptor, the mould maker and the metal caster would have been the same person. The consistency within offerings in both wax-related and casting-related attributes suggests that, if those were different specialists, only one of each would have been involved. However, artefacts are often palimpsests where singling out individual moments of making and modification may be harder to resolve (Crown 2007; Hoyt 2006). This reality poses a challenge for attribution studies as well as an opportunity for object biographies where analytical methods can be of great aid.

A final, key challenge for science-based archaeological connoisseurship is taking the identification of individuals beyond single caches or archaeological sites. Notwithstanding their relative lack of interest in explaining these data, early connoisseurs such as Morelli, Berenson and Beazley managed to spot the hands of individual artists in disparate collections. In contrast, the bulk of the more recent studies cited in the introduction to this paper, and particularly those based on chemical analyses, have only ventured into finding individual subgroups within site assemblages; they still have to prove their ability to confidently attribute two artefacts recovered in two different sites to the same maker or batch. Doing so will require great degrees of analytical precision and diagnostic fingerprints, but this should not be an insurmountable task. In the particular case of the Muisca, such an approach may allow new insight into the extent to which makers of votive offerings and those involved in creating jewellery may or may not have been the same artisans (cf. Langebaek 1987b).

\section{Conclusion}

This study has revisited the worth of focusing on the archaeological individual, and explored the potential to achieve this through the study of the manufacture and chemical composition of artefacts. Inspired by art historical connoisseurship but emphasising archaeological questions and empirical methods, we illustrated the challenge of the 'attribution postulate', which requires a step further than the traditional provenance postulate (Weigand et al. 1977): namely, that variability from a pair of hands should be smaller than variability between pairs of hands, even if these work in the same source region. Using Muisca votive goldwork as a case in point, we illustrated how instrumental data can be used to identify individual agency and single manufacturing events beneath the broader 'provenance regions', 'technological traditions' and 'styles' of mainstream archaeology. Science-based archaeological connoisseurship may help reinvigorate the role of individual agents in archaeological narratives about prehistoric societies. The change in analytical scale may also allow us to better understand craft organisation and knowledge transmission in specific artisanal workshops within broader traditions. With larger sample sizes, it may be possible to map these in time and space. Considering the growing availability of fast, cost-effective means for 
chemical and microscopic analyses of material culture, as well as for image capture and texture or morphometric analyses in large datasets, we envisage a leading role of archaeological science methods in the study of agency in archaeology. The individual hands of numerous artisans lie behind archaeological and art historical collections worldwide, awaiting discovery.

\section{Acknowledgements}

We are very grateful to the staff at the Museo del Oro in Bogotá for providing an exceptionally supportive environment for this project and sharing skills and ideas with us, especially Eduardo Londoño L., Juanita Sáenz Samper, Juan Pablo Quintero Guzmán and Clark Manuel Rodríguez. At other institutions, we would like to acknowlege comments and bibliography from Paul Craddock, David Dungworth, Ana María Falchetti, Maria Filomena Guerra, Stuart Page, Ernst Pernicka, Thilo Rehren, Salvador Rovira and Izumi Shimada, and editorial support from Louise lles and Agnese Benzonelli. The analyses of metal objects by LA-ICP-MS were led by Verena Leusch under the supervision of Ernst Pernicka, and the glass sample was analysed by Matthew Phelps. This research was supported by a British Academy grant for the project "The Muisca metallurgist in context" (SG54242).

\section{References}

Ainsworth, M.W., 2005. From Connoisseurship to technical history: the evolution of the interdisciplinary study of art. The Getty Conservation Newsletter, 20 (1), 4-10.

Baxter, M.J., Freestone, I.C., 2006. Log-ratio compositional data analysis in archaeometry. Archaeometry, 48, 511-531.

Bayard, D., 1978. Review of The individual in prehistory: studies in variability in style in prehistoric technologies, Hill, J.N. and Gunn, J. (Eds.). Man 13 (4), 679-80.

Beazley, J.D., 1956. Attic black-figure vase-painters. New York (NY): Oxford University Press.

Beazley, J.D., 1963. Attic red-figure vase-painters. Oxford (UK): Oxford Clarendon Press.

Beazley, J.D., 1971. Paralipomena. Oxford (UK): Oxford University Press.

Berenson, B., 1902. The study and criticism of Italian art. London: George Bell and Sons.

Bevan, A., Li, X., Martinón-Torres, M., Green, S., Xia, Y., Zhao, K., Zhao, Z., Ma, S., Cao, W., Rehren, T., 2014. Computer vision, archaeological classification and China's terracotta warriors. Journal of Archaeological Science, 49, 249-254.

Bezúr, A., 2003. Variability in Sicán copper alloy artifacts: its relation to material flow patterns during the middle Sicán period in Peru, AD 900-1200. Unpublished PhD thesis. Department of Materials Science and Engineering, The University of Arizona. 
Blackman, M.J., Stein, G.J., Vandiver, P.B. 1993. The standardization hypothesis and ceramic mass production: technological, compositional, and metric indexes of craft specialization at Tell Leilan, Syria. American Antiquity, 58 (1), 60-80.

Boada Rivas, A. M. 2006. Patrones de asentamiento regional y sistemas de agricultura intensiva en Cota y Suba, Sabana de Bogotá (Colombia). Bogota (CO): Fundación de Investigaciones Arqueológicas Nacionales, Banco de La República.

Bray, W., 1993. The techniques of gilding and surface-enrichment in pre-Hispanic American metallurgy, in: La Niece, S., Craddock, P. T. (Eds.), Metal Plating and Patination: Cultural and Historical Developments. Oxford (UK): Butterworth-Heinemann Ltd, pp. 182-192.

Cahen, D., Keeley, L. H., Van Noten, F.L., 1979. Stone tools, toolkits, and human behavior in prehistory. Current Anthropology, 20 (4), 661-683.

Carrier, D., 2003. In praise of connoisseurship. The Journal of Aesthetics and Art Criticism, 61, 159169.

Crown, P.L., 2007. Life histories of pots and potters: situating the individual in archaeology. American Antiquity, 72 (4), 677-69.

Dungworth, D., Loaring, A., 2009. The composition of late $16^{\text {th }}$ century to early $19^{\text {th }}$ century window glass: the Shaw House Project, in: Janssens, K., Degryse, P., Cosyns, P., Caen, J., Van't dack, L. (Eds.), Annals of the $17^{\text {th }}$ Congress of the AlHV. Antwerp (BE): Aspeditions, pp. 7-12.

Falchetti, A.M., 2003. The seed of life: the symbolic power of gold-copper alloys and metallurgical transformations, in: Quilter, J., Hoopes, J.W. (Eds.), Gold and Power in Ancient Costa Rica, Panama, and Colombia. Washington (DC): Dumbarton Oaks Research Library and Collection, pp. 345-381.

Freestone, I., Kunicki-Goldfinger, J., Gilderale-Scott, H., Ayers, T., 2010. Multi-disciplinary investigation of the windows of John Thornton, focusing on the Great East Window of York Minster, in: Shepard, M. B., Pilosi, L., Strobl, S. (Eds.), The art of collaboration: stained glass conservation in the twenty-first century. Turnhout (BE): Harvey Millar, pp. 151-158.

Freestone, I., Price, J., Cartwright, C., 2009a. The batch: its recognition and significance. Annales du 17eme Congrès de l'Association Internationale pour l'Histoire du Verre, 130-135.

Freestone, I., Yegingil, Z., Arik, R., 2009b. Scientific analysis of glazed tile from the Seljuq palace of Kubad-Abad, Lake Beysehir, Turkey, in: McCarthy, B., Chase, E. S., Allis, L. (Eds.), Scientific research on historic Asian artefacts: proceedings of the Fourth Forbes Symposium at the Freer Gallery of Art. London (UK) and Washington (DC): Archetype in association with the Freer Gallery of Art, pp. 3-8.

Gamble, C.S., Porr, M. (Eds.), 2005. The hominid individual in context: archaeological investigations of lower and middle Palaeolithic landscapes, locales and artefacts. London (UK): Routledge.

Getz-Gentle P., 2001. Personal styles in early Cycladic sculpture. Madison (WI): The University of Wisconsin Press. 
Getz-Preziosi, P., 1987. Sculptors of the Cyclades: individual and tradition in the third millennium B.C.. Ann Arbor (MI): University of Michigan Press.

Goren, Y., Mommsen, H., Klingeret, J., 2011. Nondestructive provenance study of cuneiform tablets using portable X-ray fluorescence (pXRF). Journal of Archaeological Science, 38, 684-696.

Henderson, H., Ostler, N., 2005. Muisca settlement organization and chiefly authority at Suta, Valle de Leyva, Colombia: A critical appraisal of native concepts of house for studies of complex societies. Journal of Anthropological Archaeology, 24, 148-178.

Hermens, E., 2012. Technical art history: the synergy of art, conservation and science, in: Lenain, T., Locher, H., Pinotti, A., Rampley, M., Schoell-Glass, C., Zijlmans, K. (Eds.), Art History and Visual Studies in Europe: Transnational Discourses and National Frameworks. Leiden (NL): Brill, pp. 151166.

Hill, J.N., Gunn, J. (Eds.), 1977. The Individual in prehistory: studies of variability in style in prehistoric technologies. New York (NY): Academic Press.

Hodder, I., 2000. Agency and individuals in long-term processes, in: Dobres, M.A., Robb, J., Agency in Archaeology. London (UK): Routledge, pp. 21-33.

Hosler, D., 1994. The sounds and colors of power: the metallurgical technology of ancient West Mexico. Cambridge (MA): MIT Press.

Hoyt, S.A., 2006. Masters, pupils and multiple images in Greek red-figure vase painting. PhD Thesis. Ohio State University.

Kaplan, F.S., 1980. Review of The individual in prehistory: studies of variability in style in prehistoric technologies, Hill, J.N. and Gunn, J. (Eds.). American Anthropologist, 82 (2), 418-20.

Knapp, A. B., Van Dommelen, P., 2008. Past practices: rethinking individuals and agents in archaeology. Cambridge Archaeological Journal, 18 (01), 15-34.

Kovacs, R., Schlosser, S., Staub, S. P., Schmiderer, A., Pernicka, E., \& Günther, D., 2009.

Characterization of calibration materials for trace element analysis and fingerprint studies of gold using LA-ICP-MS. Journal of Analytical Atomic Spectrometry, 24 (4), 476-483.

Kunicki-Goldfinger, J., Kierzek, K., Freestone, I. C., Małożewska-Bućko, B., Nawrolska, G., 2009. The composition of window glass from the cesspits in the Old Town in Elbląg, Poland, in: Ignatiadou, D., Antonaras, A. (Eds.), Annals du 18e Congrès de l'AlHV. Thessaloniki, pp. 395-400.

Kurtz, D.C., Beazley, J.D., 1983. The Berlin painter. Oxford (UK): Clarendon Press.

Langebaek, C.H., 1987a. Mercados, poblamiento e integración étnica entre los Muiscas: siglo XVI. Bogotá (CO): Colección Bibliográfica Banco de la República.

Langebaek, C.H., 1987b. Persistencia de prácticas de orfebrería Muisca en el siglo XVI: el caso de Lenguazaque. Universitas Humanistica, 16 (27), 45-52. 
Langebaek, C.H., 1995. Regional archaeology in the Muisca territory: a study of the Fúquene and Susa Valleys. Pittsburgh (PA)/Bogotá (CO): University of Pittsburgh/Universidad de los Andes.

Langebaek, C.H., 2005. Fiestas y caciques muiscas en El Infiernito, Colombia: un análisis de la relación entre festejos y organización política. Boletín de Arqueología PUCP, 9, 281-95.

Langebaek, C.H., Bernal, M., Aristizabal, L., Corcione, M.A., Rojas, C., Santa, T., 2011. Condiciones de vida y jerarquías sociales en el norte de Suramerica: el caso de la población muisca en Tibanica, Soacha. Indiana, 28, 15-34.

Li, X., Martinón-Torres, M., Meeks, N., Xia, Y., 2012. Scanning electron microscopy imaging of tool marks on Qin bronze weapons using silicone rubber impressions, in: Meeks, N., Cartwright, C., Meek, A., Mongiatti, A. (Eds.) Historical technology, materials and conservation: SEM and microanalysis. London (UK): Archetype \& British Museum, pp. 62-68.

Li, X.J., Bevan, A., Martinón-Torres, M., Rehren, T., Cao, W., Xia, Y., \& Zhao, K., 2014. Crossbows and imperial craft organisation: the bronze triggers of China's Terracotta Army. Antiquity, 88 (339), 126140.

Lleras Pérez, R., 1999. Prehispanic metallurgy and votive offerings in the Eastern Cordillera Colombia. BAR International Series 778. Oxford (UK): Archaeopress.

Londoño, E., 1989. Santuarios, santillos, tunjos: objetos votivos de los muiscas en el siglo XVI. Boletín Museo del Oro, 25, 93-119.

Marcus, J., 2015. Studying the individual in Prehistory: a tale of three women from Cerro Azul, Peru. Ñawpa Pacha, 35 (1), 1-22.

Martinón-Torres, M., Li, X.J., Bevan, A., Xia, Y., Zhao, K., Rehren, T., 2014. Forty thousand arms for a single emperor: from chemical data to the labor organization behind the bronze arrows of the Terracotta Army. Journal of Archaeological Method and Theory, 21 (3), 534-562.

Martinón-Torres, M., Uribe-Villegas, M.A., 2015. Technology and culture in the invention of lost-wax casting in South America: an archaeometric and ethnoarchaeological perspective. Cambridge Archaeological Journal, 25, 377-390.

Martinón-Torres, M., Valcárcel Rojas, R., Sáenz Samper, J., Filomena Guerra, M., 2012. Metallic encounters in Cuba: the technology, exchange and meaning of metals before and after Columbus. Journal of Anthropological Archaeology, 31 (4), 439-454.

Morelli, G., 1892-3. Italian Painters: Critical Studies of their Works. London (UK): John Murray.

Morris, C., 1993. Hands up for the individual! The role of attribution studies in Aegean prehistory. Cambridge Archaeological Journal, 3, 41-66.

Mugnaini, S., Giamello, M., Pisani, A., Siano, S., 2014. Casting cores used to craft large bronze masterpieces of the Florentine Renaissance and Mannerism. Journal of Archaeological Science, 47, 85-98. 
Olivier, J. P., 1967. La série Dn de Cnossos. Studia Micenei ed Egeo-Anatolici, 2, 71-93.

Opperman, H., 1990. The thinking eye, the mind that sees: the art historian as connoisseur. Artibus et Historiae, 11 (21), 9-13.

Pigeot, N., 1990. Technical and social actors. Flintknapping specialists and apprentices at Magdalenian Etiolles. Archaeological Review from Cambridge, 9 (1), 126-141.

Plog, F., 1977. Archaeology and the individual, in: Hill, J.N., Gunn, J. (Eds.), The individual in prehistory: studies of variability in style in prehistoric technologies. New York (NY): Academic Press, pp. 13-21.

Rehren, T., Kraus, K., 1999. Cupel and crucible: the refining of debased silver in the Colonia Ulpia Traiana, Xanten. Journal of Roman Archaeology, 12, 263-72.

Reichel-Dolmatoff, G., 1978. Desana animal categories, food restrictions, and the concept of color energies. Journal of Latin American Lore, 4 (2), 243-91.

Reichel-Dolmatoff, G., 1981. Things of beauty replete with meaning - metals and crystals in Colombian Indian cosmology, in: Sweat of the sun, tears of the moon: gold and emerald treasures of Colombia. Los Angeles (CA): Natural History Museum Alliance of Los Angeles Country, pp. 17-33.

Roux, V. 2010. Technological innovations and developmental trajectories: social factors as evolutionary forces, in: O'Brien, M.J., Shennan, S.J. (Eds.), Innovations in cultural systems: contributions from evolutionary anthropology. Cambridge, Mass.: MIT Press, pp. 217-234.

Saunders, N., 2011. Shimmering worlds: brilliance, power, and gold in pre-Columbian Panama, in: Hoopes, J.W., Quilter, J., Saunders, N.J., Cooke, R.G. (Eds.), To capture the sun: Gold of ancient Panama. Tusla (OK): Gilcrease Museum and University of Tulsa, pp. 78-113.

Schalm, O., Janssens, K., Wouters, H., Caluwé, D., 2007. Composition of $12-18^{\text {th }}$ century window glass in Belgium: Non-figurative windows in secular buildings and stained-glass windows in religious buildings. Spectrochimica Acta Part B, 62, 663-668.

Shennan, S. 2013. Lont-term trajectories of technological change, in: Richerson, P.J., Christiansen, M.H. (Eds.), Cultural evolution: Society, technology, language and religion. Cambridge, Mass.: MIT Press, pp. 143-155.

Shimada, I., Wagner, U., 2007. A holistic approach to pre-Hispanic craft production, in: Skibo, J. M., Graves, M. W., Stark, M. T. (Eds.), Archaeological Anthropology: Perspectives on Method and Theory.Tucson (AZ): University of Arizona Press, pp. 163-195.

Simón, P., 1981 [1527]. Noticias historiales de las conquistas de Tierra Firme en las Indias Occidentales, vols. I-III, Bogotá (CO): Banco Popular.

Therrien, M., 2001. Análisis de material vítreo, ofrendatario muisca de Tocancipá, Colección Museo del Oro. Unpublished manuscript. Bogotá (CO): Archivo Museo del Oro, Banco de la República. 
Torres, W., 1985. Lectura de Espacios. Etnología de espacios del saber. Unpublished thesis. Bogotá (CO): Departamento de Antropología, Universidad Nacional de Colombia.

Thomas, J.T., McCall, G., Lillios, K.T., 2009. Revisiting the individual in prehistory: idiosyncratic engraving variation and the Neolithic slate plaques of the Iberian Peninsula. Cambridge Archaeological Journal, 19 (2), 53-72.

Uribe-Villegas, M.A., 2012. Contexto, significado y color en la selección de materiales en la orfebrería muisca. Un estudio analítico e interpretativo de la composición química de artefactos. Boletín de Arqueología, 23. Bogotá (CO): Fundación de Investigaciones Arqueológicas Nacionales.

Uribe-Villegas, M.A., Londoño, E., Quintero, J.P., Martinón-Torres, M., Morales, J., 2013. Historias de ofrendas Muiscas. Catálogo virtual de la exposición temporal en el Museo del Oro, Bogotá D.C.

Bogotá (CO): Banco de la República. URL: http://www.banrepcultural.org/museo-deloro/exposiciones-temporales/historias-de-ofrendas-muiscas.

Uribe-Villegas, M.A., Martinón-Torres, M., 2012a. Composition, colour and context in Muisca votive metalwork (Colombia, AD 600-1800). Antiquity, 86, 772-791.

Uribe-Villegas, M.A., Martinón-Torres, M., 2012b. Typology, technology, composition and context of Muisca metalwork (Colombia, AD 600-1800): a database. Journal of Open Archaeology Data, 1 (1). Doi: $10.5334 /$ data.1331810205.

Van Keuren, S., 1999. Ceramic design structure and the organization of Cibola white ware production in the grasshopper region, Arizona. Arizona State Museum Archaeological Series, 191, 86-104.

Van Stone, M., 2001. Identifying individual hands in the monuments of K'inich Ahkal Mo' Naab of Palenque. Report submitted to FAMSI (Foundation for the Advancement of Mesoamerican Studies, Inc). URL: <http://www.famsi.org/reports/99027/>.

Watts, J., 2013. Traces of the Individual in Prehistory: Flintknappers and the distribution of projectile points in the eastern Tonto Basin, Arizona. Advances in Archaeological Practice, 1, 25-36.

Weigand, P.C., Harbottle, G., Sayre, E.V., 1977. Turquoise sources and source analysis: Mesoamerica and the southwestern U.S.A., in: Earle, T.K., Ericson, J.E. (Eds.), Exchange systems in prehistory. New York (NY): Academic Press, pp. 15-34.

White, C.L., 2009. The Materiality of Individuality. New York (NY): Springer.

Whittaker, J., 1987. Individual variation as an approach to economic organization: projectile points at grasshopper pueblo, Arizona. Journal of Field Archaeology, 14 (4), 465-479.

Wollheim, R., 1973. Giovanni Morelli and the origins of scientific connoisseurship, in: Wollheim, R. (Ed.), On Art and the Mind: Essays and Lectures. London (UK): Allen Lane, pp. 177-201.

Yuan Zhongyi, 2014. Qin bingmayong de kaogu faxian yu yanjiu (Archaeological Discoveries and Research on the Qin Terracotta Warriors). Beijing: Wenwu Press. 